\title{
ANALISIS FAKTOR YANG MEMPENGARUHI OUTCOME PASIEN CEDERA KEPALA BERDASARKAN FUNCTIONAL INDEPENDENCE MEASURE (FIM)
}

\author{
Moh. Ubaidillah Faqih ${ }^{1}$, Ahsan $^{2}$, Tina Handayani Nasution ${ }^{3}$ \\ ${ }^{1}$ Program Studi Magister Keperawatan Fakultas Kedokteran Universitas Brawijaya \\ 2,3Fakultas Kedokteran Universitas Brawijaya \\ Jalan Veteran Malang 65145 \\ Email: moh.ubaidillah.faqih@gmail.com
}

\begin{abstract}
Head injuries caused by traffic accidents are the main cause of disability and mortality. FIM is one outcome measurement head injury. Several suspected factors are age, mechanism of injury, initial GCS score, hypotension, pupil diameter and the light reactions, CT scan, alcohol use, as well as the duration of treatment. The purpose of this study was to determine the factors that influence the outcome of head injury by FIM in patients with head injury. This study is an observational analytic study using a retrospective design of the 107 samples of medical records dr. R. Koesma Tuban from the period January to April 2016. The data was collected using cluster random sampling technique with the inclusion and exclusion criteria. The instrument use a basic collection sheets, checklists and sheets FIM. Data analysis use contingency coefficient test and logistic regression. Logistic regression analysis showed that factors affecting is GCS $(p=0.996)$ and pupil $(p=0.077)$. The equation obtained $y=0.357+19.434$ (GCS) $+2,041$ (Pupil). Hosmer and Lameshow test results showed good calibration ( $p=1.000)$, AUC value of $93.6 \%$ indicates that the regression equation obtained capable of distinguishing the outcome of head injury by variables GCS and pupils, the remaining $6.4 \%$ is influenced by other factors. The conclusion of this study is the initial GCS score and pupil is a dominant factor influence the outcome by FIM. Therefore, nurses need to improve the management of head injury patients in the emergency phase by measuring GCS and pupils more thoroughly.
\end{abstract}

\section{Keywords: outcome, head injury, Functional Independence Measure (FIM)}

Abstrak: Cedera kepala akibat kecelakaan lalu lintas merupakan penyebab utama disabilitas dan mortalitas. FIM merupakan salah satu pengukuran outcome cedera kepala. Beberapa faktor yang dicurigai adalah usia, mekanisme cedera, skor awal GCS, hipotensi, diameter pupil dan reaksi cahaya, CTscan, penggunaan alkohol, serta lama perawatan. Tujuan penelitian ini adalah mengetahui faktor yang mempengaruhi outcome cedera kepala berdasarkan FIM pada pasien cedera kepala. Penelitian ini adalah studi yang bersifat analitik observasional dengan menggunakan rancangan retrospektif terhadap 107 sampel rekam medis RSUD dr. R. Koesma Tuban dari periode Januari-April 2016. Pengumpulan data menggunakan tehnik cluster random sampling dengan kriteria inklusi dan ekslusi. Instrumen yang akan digunakan lembar pengumpulan dasar, checklist dan lembar FIM. Analisis menggunakan uji koefisien kontingensi dan regresi logistik. Hasil uji regresi logistik menunjukan faktor yang mempengaruhi adalah GCS $(p=0,996)$ dan pupil $(p=0,077)$. Persamaan yang didapat adalah $y=0,357+19,434$ (GCS) $+2,041$ (Pupil). Hasil uji Hosmer and Lameshow menunjukan kalibrasi yang baik $(p=1,000)$, nilai AUC menunjukan bahwa $93,6 \%$ persamaan regresi yang diperoleh mampu membedakan outcome cedera kepala berdasarkan variabel GCS dan pupil, sisanya yaitu 6,4\% dipengaruhi oleh faktor lain. Kesimpulan dari penelitian ini adalah skor awal GCS dan pupil menjadi faktor yang dominan berpengaruh dengan outcome berdasarkan FIM. Oleh karena itu, perawat perlu meningkatkan manajemen pasien cedera kepala pada fase emergency dengan melakukan pengukuran GCS dan Pupil secara lebih teliti.

Kata kunci : outcome, cedera kepala, Functional Independence Measure (FIM)

\section{PENDAHULUAN}

Kecelakaan lalu lintas dapat mengakibatkan berbagai cedera. Cedera yang paling banyak terjadi pada saat kecelakaan lalu lintas adalah cedera kepala. Cedera kepala akibat kecelakaan lalu lintas merupakan penyebab utama disabilitas dan mortalitas di negara berkembang. Keadaan ini umumnya terjadi pada pengemudi motor tanpa helm atau memakai helm yang kurang tepat dan yang tidak memenuhi standar (Wijayanti,2012). 
Wilayah kabupaten Tuban dilewati jalur utama pantura yang menghubungkan Surabaya-Semarang-Jakarta. Tingginya volume kendaraan dapat mengakibatkan timbulnya kemacetan dan dapat menimbulkan masalah lain seperti kejadian kecelakaan lalu lintas. Jalur pantura Wilayah Tuban yang meliputi ruas jalan Tuban Widang, Jl. Manunggal, Jl. Panglima Sudirman, Jl. RE. Martadinata dan Jl.Tuban Semarang memiliki masalah kejadian kecelakaan yang cenderung meningkat. Berdasarkan data tahun 2009-2013, kejadian kecelakaan lalu lintas pada jalur pantura yang melewati wilayah Tuban cenderung mengalami peningkatan. Jumlah kecelakaan lalu lintas selama tahun 20092013 sebanyak 1.107 kejadian. Akibat dari kecelakaan yaitu korban meninggal dunia 208 jiwa, korban luka berat 249 dan korban luka ringan sebanyak 1.147 jiwa. Tahun 2012 memiliki jumlah kecelakaan lalu lintas tertinggi yaitu sebanyak 348 atau $31,4 \%$ kejadian dengan rincian korban meninggal dunia 45 jiwa, korban luka berat 65 jiwa dan korban yang mengalami luka ringan sebanyak 411 jiwa. Secara garis besar, jumlah kecelakaan lalu lintas selama tahun 2009-2013 ratarata mengalami peningkatan $17,03 \%$ per tahun (Rosyida, et al., 2015).

Outcome didefinisikan sebagai sebuah perubahan menjadi situasi tertentu yang dihasilkan dari sebuah aksi yang terjadi. Kata outcome digunakan untuk sequele, konsekuensi, dan hasil akhir atau temuan spesifik lain yang terjadi akibat cedera kepala. Awal keparahan klinis, lesi otak pada temuan pencitraan dan outcome lebih parah terjadi pada cedera otak traumatis yang tidak disengaja. (Sastrodiningrat, 2006).

Beberapa faktor kemungkinan berpengaruh adalah usia, mekanisme cedera, skor awal Glasgow Coma Scale (GCS), hipotensi, diameter pupil dan reaksi cahaya, computed tomography (CT) scan, penggunaan alkohol dan obatobat (Jiang, 2012). Faktor-faktor seperti usia, jenis kelamin, keparahan cedera, kematian di rumah sakit, jenis asuransi dan lokasi rumah sakit sebagai prediktor biaya rumah sakit dan lama perawatan untuk cedera (Gardner, et al., 2007). Penilaian outcome secara tepat diperoleh pada 3, 6 dan 12 bulan setelah cedera otak. Kondisi pasien yang membaik signifikan secara klinis terutama 6 bulan setelah cedera otak (Arnold, 2013).

Banyak macam skala pengukuran outcome dari cedera kepala, diantaranya Glasgow Outcome Scale (GOS), Barthel Index (BI), dan Functional Independence Measure (FIM) (Hadi, 2014). Functional independence measure (FIM) merupakan alat ukur yang digunakan untuk menilai ketergantungan pasien. Alat ukur ini bisa dipakai secara umum oleh semua pihak, yaitu dokter, perawat, fisioterapis, pasien atau keluarga. Penilaiannya meliputi kemampuan fisik atau motorik termasuk fungsi vegetatif- dan kemampuan kognisi berupa komunikasi serta interaksi dengan orang di sekitarnya (Van Middendorp; et al., 2011).

Tujuan penelitian ini adalah mengetahui faktor yang mempengaruhi outcome cedera kepala berdasarkan Functional Independence Measure (FIM) pada pasien cedera kepala yang pernah dirawat di IGD RSUD dr. R. Koesma Tuban.

\section{METODE PENELITIAN}

Penelitian ini adalah studi yang bersifat analitik observasional dengan menggunakan rancangan retrospektif terhadap 107 sampel rekam medis RSUD dr. R. Koesma Tuban dari periode Januari-April 2016 yang kemudian dilakukan kunjungan rumah untuk menilai outcome cedera kepala berdasarkan Functional Independence Measure (FIM). Pengumpulan data menggunakan tehnik cluster random sampling dengan kriteria inklusi: 1) Pasien masih hidup, 2) Pasien dengan gangguan imobilisasi, 3) Pasien yang $\leq 6$ bulan, 3) Pasien yang berdomisili di Kabupaten Tuban, 4) Pasien bersedia menjadi responden.

Penelitian ini juga mengekslusi rekam medis pasien cedera kepala dengan rujukan $>48$ jam dari kejadian cedera dan pasien cedera kepala disertai gangguan lainya. Instrumen yang akan digunakan adalah lembar pengumpulan 
dasar, checklist dan lembar FIM. Analisis bivariat menggunakan uji koefisien kontingensi, sedangkan analisis multivariat menggunakan uji regresi logistik.

\section{HASIL PENELITIAN}

Berdasarkan data IGD RSUD dr. R. Koesma Tuban angka kejadian trauma dan kegawatdaruratan akibat kecelakaan di daerah Pantai Utara (Pantura) meningkat sebesar 5\% dari tahun 2014 dan pada Bulan Januari sampai dengan April 2016, kunjungan pasien karena cedera kepala secara umum berjumlah 175 kasus (100\%); kasus yang terbanyak karena kecelakaan lalu lintas berjumlah 86 kasus $(55,8 \%)$ dan responden yang berdomisili di kabupaten Tuban berjumlah 146 kasus $(83,4 \%)$ yang selanjutnya menjadi populasi dalam penelitian ini.

Penelitian ini dilaksanakan pada bulan Mei sampai Juli 2016 di RSUD dr. R. Koesma Tuban dengan mengumpulkan data awal tentang usia, mekanisme cedera, hipotensi, GCS, keadaan pupil, hasil pemeriksaan $C T$ scan, konsumsi alkohol, lama hari rawat di Rumah Sakit dari rekam medis dan menetapkan populasi cedera kepala yang pernah dirawat di IGD yaitu sebanyak 146 responden. Penyajian hasil penelitian dianalisis berdasarkan analisis univariat, analisis bivariat dan analisis multivariat.

\section{Tabel 1 Distribusi Frekuensi Karakteristik Responden Berdasarkan Jenis Kelamin, Usia, dan Cedera Kepala}

\begin{tabular}{lcc}
\hline \multicolumn{1}{c}{ Karakteristik } & $\mathrm{n}$ & $\%$ \\
\hline Jenis Kelamin & & \\
\hline Laki-laki & 59 & 55,1 \\
\hline Perempuan & 48 & 44,9 \\
\hline Usia & & \\
\hline 1-4 tahun & 1 & 0,9 \\
\hline 5-14 tahun & 17 & 15,9 \\
\hline 15-24 tahun & 26 & 24,3 \\
\hline 25-44 tahun & 29 & 27,1 \\
\hline 45-59 tahun & 21 & 19,6 \\
\hline$>59$ tahun & 13 & 12,1 \\
\hline Cedera Kepala & & \\
\hline Ringan & 78 & 72,9 \\
\hline Berat & 29 & 27,1 \\
\hline Total & 107 & 100,0 \\
\hline
\end{tabular}

Sumber : Data Primer (2016)

Berdasarkan tabel 1, dapat diketahui bahwa jumlah responden yang mengalami cedera kepala dan yang pernah dirawat di IGD RSUD dr. R. Koesma Tuban, terbanyak adalah laki-laki dengan jumlah 59 responden $(55,1 \%)$, usia $15-24$ tahun dengan jumlah 29 responden $(27,1 \%)$ dan cedera kepala ringan dengan jumlah 78 $(72,9 \%)$.

Tabel 2 Hasil Analisa Bivariat Koefisien Kontingensi

\begin{tabular}{cccc}
\hline Variabel & $\mathbf{n}$ & $\boldsymbol{r}$ & $\boldsymbol{p}$ \\
\hline Usia & 107 & 0,101 & 0,953 \\
\hline Cedera & 107 & 0,117 & 0,223 \\
\hline Hipotensi & 107 & 0,032 & 0,744 \\
\hline GCS & 107 & 0,423 & 0,000 \\
\hline Pupil & 107 & 0,360 & 0,000 \\
\hline CTscan & 107 & 0,066 & 0,492 \\
\hline Alkohol & 107 & 0,130 & 0,174 \\
\hline Lama Rawat & 107 & 0,351 & 0,000 \\
\hline \multicolumn{4}{c}{ Sumber : Data Primer $(2016)$}
\end{tabular}

Berdasarkan tabel 2, dapat diketahui bahwa variabel yang tidak berhubungan dengan FIM adalah usia $(p=0,953)$, mekanisme cedera $(p=0,223)$, hipotensi $(0,744)$, pemeriksaan $C T$ scan $(p=0,492)$, dan konsumsi alkohol $(p=0,174)$. Sedangkan variabel yang berhubungan adalah GCS $(p<0,001)$, diameter pupil $(p<0,001)$, dan lama perawatan di Rumah Sakit $(p<0,001)$.

Berdasarkan Tabel 3, dapat diketahui bahwa variabel yang berpengaruh terhadap kemandirian (outcome cedera kepala berdasarkan Functional Independence Measure (FIM)) adalah GCS $(p=0,996)$ dan pupil $(p=0,077)$. Kekuatan hubungan dari yang terbesar ke yang terkecil adalah GCS $(\mathrm{OR}=275390993,19)$ dan pupil $(\mathrm{OR}=7,70)$.

Untuk menilai probalitas kemandirian responden (outcome cedera kepala berdasarkan Functional Independence Measure (FIM)) dalam penelitian ini, dihitung menggunakan rumus persamaan:

$$
\begin{aligned}
& y=\text { konstanta }+a_{1} x_{1}+a_{2} x_{2}+\ldots .+a_{i} x_{i} \\
& \text { dan } \\
& p=1 /\left(1+e^{-y}\right)
\end{aligned}
$$


Tabel 3 Hasil Analisa Multivariat Regresi Logistik

\begin{tabular}{clccc}
\hline & \multicolumn{1}{c}{ Variabel } & Koefisien & $P$ & OR \\
\hline Langkah 1 & GCS Ringan & 18,454 & 0,996 & 103401604,41 \\
\hline & Pupil Isokor & 1,435 & 0,227 & 4,20 \\
\hline & Lama Rawat $<3$ & 16,437 & 0,997 & 13751925,87 \\
\hline & Konstanta & 0,357 & 0,469 & 1,429 \\
\hline Langkah 2 & GCS Ringan & 19,434 & 0,996 & 275390993,19 \\
\hline & Pupil Isokor & 2,041 & 0,077 & 7,70 \\
\hline Konstanta & 0,357 & 0,469 & 1,429 \\
\hline & & & Sumber: Data Primer (2016)
\end{tabular}

Keterangan:

$$
\begin{aligned}
& \mathrm{a}=\text { nilai koefisien tiap variabel } \\
& \mathrm{x}=\text { nilai variabel bebas } \\
& \mathrm{p}=\text { probabilitas } \\
& \mathrm{e}=\text { bilangan natural }=2,7
\end{aligned}
$$

Categorical dependent variable coding:

$\begin{array}{ll}\text { GCS } & : 1 \text { "Ringan"; } 0 \text { "Berat" } \\ \text { Pupil } & \vdots \quad 1 \quad \text { "Isokor"; } 0 \\ \text { Lama rawat }: 1 \text { " } 1<3 \text { "; } 0 \text { " }>3 \text { " }\end{array}$

Dengan demikian, probabilitas responden untuk mandiri apabila pengukuran GCS awal menunjukan hasil yang ringan dan pupil isokor adalah 100\%. Sedangkan apabila pasien cedera kepala dengan GCS berat dan pupil anisokor, maka probabilitas pasien tersebut untuk menjadi mandiri adalah $58,8 \%$.

Tabel 4 Hasil Uji Hosmer and Lameshow

\begin{tabular}{ccc}
\hline Chi-square & df & Sig \\
\hline 0,000 & 3 & 1,000 \\
\hline 0,000 & 2 & 1,000 \\
\hline
\end{tabular}

Berdasarkan hasil uji Hosmer and Lameshow pada tabel 5.12, persamaan y $=0,357+19,434$ (GCS) $+2,041$ (Pupil) memiliki kualitas persamaan yang menunjukan kalibrasi yang baik dengan nilai signifikansi yang didapatkan $(1,000)$, dimana lebih dari 0,05 . Hal ini menunjukan bahwa uji Hosmer and Lameshow dipenuhi, maka model persamaan yang didapatkan melalui hasil perkalian antara nilai regresi $(19,434)$ dengan faktor GCS yang bernilai 1 apabila GCS ringan dan bernilai 0 apabila GCS berat, ditambah dengan hasil perkalian nilai regresi $(2,041)$ dengan faktor pupil yang bernilai 1 apabila pupil isokor dan bernilai 0 apabila anisokor ditambah dengan nilai konstanta sebesar 0,357 dinilai dapat memprediksi outcome cedera kepala kriteria mandiri.

\section{Tabel 5 Hasil Uji Kurva ROC}

\begin{tabular}{ccccc}
\hline \multirow{2}{*}{ Area } & $\begin{array}{c}\text { Std. } \\
\text { Error }\end{array}$ & $\begin{array}{c}\text { Asymp } \\
\text { Sig. }\end{array}$ & \multicolumn{2}{c}{ Asymptotic 95\% } \\
\cline { 4 - 5 } & $\begin{array}{c}\text { Confidence interval } \\
\text { Lower } \\
\text { Bound }\end{array}$ & $\begin{array}{c}\text { Upper } \\
\text { Bound }\end{array}$ \\
\hline 0,936 & $\begin{array}{c}0,02 \\
9\end{array}$ & 0,000 & 0,871 & 0,983 \\
\hline
\end{tabular}

Berdasarkan tabel 5, maka didapatkan nilai Area Under Curve (AUC) sebesar $93,6 \%$ yang berarti bahwa nilai diskriminan dari model persamaan ini sangat kuat. Hal ini menunjukan bahwa $93,6 \%$ persamaan regresi yang diperoleh mempu membedakan outcome cedera kepala berdasarkan variabel GCS dan pupil, sisanya yaitu $6,4 \%$ dipengaruhi oleh faktor lain yang tidak diteliti dalam penelitian ini.

\section{PEMBAHASAN}

Berdasarkan tabel 2, dapat diketahui bahwa variabel yang tidak berhubungan dengan FIM adalah sia $(p=0,953)$, mekanisme cedera $(p=0,223)$, ipotensi $(0,744)$, Pemeriksaan CTscan $(p=0,492)$, onsumsi alohol $(p=0,174)$. Hal ini disebabkan kerena penyebaran kategori FIM baik yang tergantung maupun mandiri merata diseluruh variabel (usia, mekanisme cedera, hipotensi, pemeriksaan CT scan, dan konsumsi alcohol) yang artinya semua keadaan memungkinan untuk mandiri sangat besar. Selain itu keadaan hipotensi yang 
dialami bisa saja karena faktor lain karena mengingat hasil pengukuran GCS dan CT scan yang tergolong dalam batas normal.

Berdasarkan tabel 3, dapat diketahui bahwa variabel yang berpengaruh terhadap kemandirian (outcome cedera kepala berdasarkan Functional Independence Measure (FIM)) adalah GCS $(p=0,996)$ dan upil $(p=0,077)$. Kekuatan hubungan dari yang terbesar ke yang terkecil adalah GCS $(\mathrm{OR}=275390993,19)$ dan upil $(\mathrm{OR}=7,70)$. Probabilitas responden untuk mandiri adalah $100 \%$. Dengan kualitas persamaan yang diperoleh mempunyai kalibrasi yang baik yaitu $p=1,000$ pada hasil Hosmer and Lameshow, sedangkan nilai diskriminasi adalah 93,6\% dengan intepretasi secara statistik adalah sangat kuat.

Derajat kesadaran tampaknya mempunyai pengaruh yang kuat terhadap kesempatan hidup dan penyembuhan. GCS juga merupakan faktor prediksi yang kuat dalam menentukan prognosa, suatu skor GCS yang rendah pada awal cedera berhubungan dengan prognosa yang buruk. Jennet dkk., melaporkan bahwa $82 \%$ dari penderita dengan skor GCS 11 atau lebih, dalam waktu 24 jam setelah cedera mempunyai good outcome atau moderately disabled dan hanya $12 \%$ yang meninggal atau mendapat severe disability. Outcome secara progresif akan menurun kalau skor awal GCS menurun. Di antara penderita-penderita dengan skor awal GCS 3 atau 4 dalam 24 jam pertama setelah cedera hanya $7 \%$ yang mendapat good outcome atau moderate disability. Di antara penderita dengan skor GCS 3 pada waktu masuk dirawat, 87\% akan meninggal (Sastrodiningrat, 2006).

Terdapat beberapa kontroversi didalam saat menentukan GCS. Penentuan skor GCS sesudah resusitasi kardiopulmonal, dapat mengurangi nilai prediksi GCS. Pada beberapa penderita, skor mata dan skor verbal sulit ditentukan pada mata yang bengkak dan tindakan intubasi endotrakeal. Skor motorik dapat menjadi prediksi yang kuat; penderita dengan skor motorik 1 (bilateral flaksid) mempunyai mortalitas $90 \%$. Adanya skor motorik yang rendah pada awal cedera dan usia diatas 60 tahun merupakan kombinasi yang mematikan (Kelly, Kordistani, \& Martin, 1996).

Kehilangan kesadaran yang lama, dalam banyak hal tidak prediktif terhadap outcome yang buruk. Groswasser dan Sazbon melakukan tinjauan penyembuhan fungsional dari 134 penderita dengan gangguan kesadaran selama 30 hari. Hampir separuhnya mempunyai ketergantungan total didalam aktifitas kehidupan sehari-hari, dan $20 \%$ yang lain mempunyai ketergantungan terbatas. Biasanya penderita yang sembuh adalah pada usia dibawah 30 tahun dengan fungsi batang otak yang baik (Groswasser \& Sazbon, 1990).

Abnormalitas fungsi pupil, gangguan gerakan ekstraokular, pola-pola respons motorik yang abnormal seperti postur fleksor dan postur ekstensor, semuanya memprediksikan outcome yang buruk setelah cedera kepala berat (NINDS, 2015). Sastrodiningrat (2006) menyatakan bahwa anisokor, refleks pupil yang tidak teratur atau pupil yang tidak bereaksi terhadap rangsang cahaya biasanya disebabkan karena kompresi terhadap saraf otak ketiga atau terdapat cedera pada batang otak bagian atas, biasanya karena herniasi transtentorial. Dalam suatu tinjauan terhadap 153 penderita dewasa dengan herniasi transtentorial, hanya $18 \%$ yang mempunyai penyembuhan yang baik. Diantara penderita dengan anisokori pada waktu masuk dirawat dengan batang otak yang tidak cedera, $27 \%$ mencapai penyembuhan yang baik, akan tetapi bila ditemukan pupil yang tidak bergerak dan berdilatasi bilateral, secara bermakna ditemukan hanya $3.5 \%$ yang sembuh. Penderita dengan pupil yang anisokor yang mendapat penyembuhan baik cenderung berumur lebih muda, dan refleks batang otak bagian atas yang tidak terganggu. 10 dari 40 (25\%) penderita dengan satu pupil berdilatasi ipsilateral terhadap suatu perdarahan subdural (PSD) mencapai penyembuhan fungsional. Seelig dkk melaporkan hanya 6 dari 61 (10\%) penderita dengan dilatasi pupil bilateral yang mencapai penyembuhan fungsional (NINDS, 2015). 


\section{KESIMPULAN DAN SARAN}

Dari hasil penelitian yang didapat, maka dapat disimpulkan bahwa variabel yang tidak berhubungan dengan outcome cedera kepala berdasarkan Functional Independence Measure (FIM) pada pasien cedera kepala yang pernah dirawat di IGD RSUD dr. R. Koesma Tuban adalah usia, mekanisme cedera, hipotensi, pemeriksaan CT Scan, konsumsi alkohol, sedangkan faktor yang berpengaruh adalah skor GCS awal dan reflek pupil.

Berdasarkan hal tersebut, maka saran yang dapat diberikan: 1) Perawat menggunakan hasil penelitian ini sebagai bahan pembuatan media informasi

\section{DAFTAR PUSTAKA}

Alligood. (2014). Nursing theorists and their work, 8th Edition. Mosby Elsevier, Inc.: St. Louis.

Arifin, M., \& Henky, J. (2012). Analisis nilai functional independence measure penderita cedera servikal dengan perawatan konservatif. Makara, Kesehatan, Vol. 16, No. 1, Juni 2012, 17-22.

Arnold, C. D. (2013). Faktor - Faktor Yang Berhubungan Dengan Outcome Pasien Pasca Operasi Hematoma Epidural (EDH). Padang: Fakultas Kedokteran Universitas Andalas.

Bethel. (2012). Emergency Care of Children and Adults With Head Injury. Nursing Standard. (43), 4956.

Canadian Partnership for Stroke Recovery. (2016). Functional Independence Measure (FIM) Evaluation Summary . Retrieved from http://www.strokengine.ca

Gardner, Smith, Chany, Fernandez, \& McKenzie. (2007). Factors associated with hospital length of stay and hospital charges of motor vehicle crash related hospitalizations among children in the United States. Arch Pediatr Adolesc Med 2007, 161(9), 889895. tentang pentingnya pengukuran GCS dan pemeriksaan reflek pupil yang dapat digunakan oleh perawat IGD sebagai upaya peningkatan manajemen pasien cedera kepala pada fase emergency; 2) Peneliti selanjutnya menggunakan hasil penelitian ini sebagai landasan atau bahan kajian untuk mengembangkan penelitian dalam ruang lingkup kasus cedera kepala dengan memperhitungkan faktor-faktor lainya yang tidak diteliti dalam penelitian ini seperti derajat keparahan cedera kepala, lokasi cedera kepala, dan perawatan selama di rumah sehingga hasil yang diperoleh akan lebih akurat.

Groswasser, Z., \& Sazbon, L. (1990). Outcome in 134 patients with prolonged posttraumatic unawareness. Part 2 : Functional outcome of 72 patients recovering consciousness. J. Neurosurg, 72 : $81-4$.

Gufron, A. (2013). Hubungan gambaran hasil CT scan dengan nilai glasgow coma scale pada pasien cedera kepala. Yogyakarta: Universitas Muhammadiyah Yogyakarta.

Hadi, J. (2014). Pengaruh koagulopati terhadap glasgow outcome scale penderita cedera kepala berat yang tidak mempunyai indikasi operasi. Padang: Universitas Andalas.

Jiang, J. (2012). Head trauma in China. Injury, Int. J.Care Injured 44 (2013) , 1453-1457.

Kelly, D., Kordistani, R., \& Martin, N. (1996). Hyperemia following traumatic brain injury. Relationship to intracranial hypertension and outcome. J Neurosurg, 85 : 762 71.

Kementerian Kesehatan Republik Indonesia. (2015). Report Kunjungan RS. Retrieved from http://sirs.buk.depkes.go.id/ 
Kementerian Perhubungan Republik Indonesia. (2015). Perhubungan darat dalam angka 2014. Jakarta: Kementerian Perhubungan Republik Indonesia.

NINDS. (2015). Traumatic Brain Injury. Maryland: NIH Publication No. 16158.

Putri, R. (2013). Analisis praktik klinik keperawatan kesehatan masyarakat perkotaan pada. Jakarta: Universitas Indonesia.

Rosyida, S. N., Daryono, \& Prasetyo, K. (2015). Kajian Kecelakaan Lalu Lintas Di Jalan Arteri Pada Jalur Pantura Wilayah Tuban. Swara Bhumi Vol 1, No 1, (2015).

Safrizal, Saanin, S., \& Bachtiar. (2013). Hubungan nilai oxygen delivery dengan outcome rawatan pasien cedera kepala sedang. Padang: Universitas Andalas.

Sastrodiningrat, A. G. (2006). Memahami Faktor-Faktor yang Mempengaruhi Prognosa Cedera Kepala Berat. Suplemen Majalah Kedokteran Nusantara Volume 39 No. 3 September 2006.

Sipayung, N. P., \& Syapitri, H. (2015). GCS sebagai prediktor lenght of stay pasien CKR di RSU Pringadi
Medan. INJEC Vol 2 No 2 Okt 2015.indd.

Sister, F. (2014). Gambaran Kadar Natrium Dan Kalium Penderita Kontusio Serebri Di Instalasi Gawat Darurat Rumah Sakit Umum Pusat Haji Adam Malik Tahun 2012. Sumatra Utara: Universitas Sumatra Utara.

Van Middendorp, J., Hosman, A., Donders, A., Pouw, M., Ditunno, J., \& Curt, A. (2011). A clinical prediction rule for ambulation outcomes after traumatic spinal cord injury: a longitudinal cohort study. The Lancet, 377(9770), 1004-1010.

WHO. (2015, Oktober). Road traffic injuries. Switzerland. Retrieved from

http://www.who.int/mediacentre/fac tsheets/fs358/en/

Wijayanti. (2012). Asuhan keperawatan pada Tn. $S$ dengan gangguan sistem persyarafan: cedera kepala post kraniotomi hari ke-2 di Ruang Sofa Rumah Sakit PKU Muhammadiyah . Surakarta: Universitas Muhammadiyah Surakarta. 